
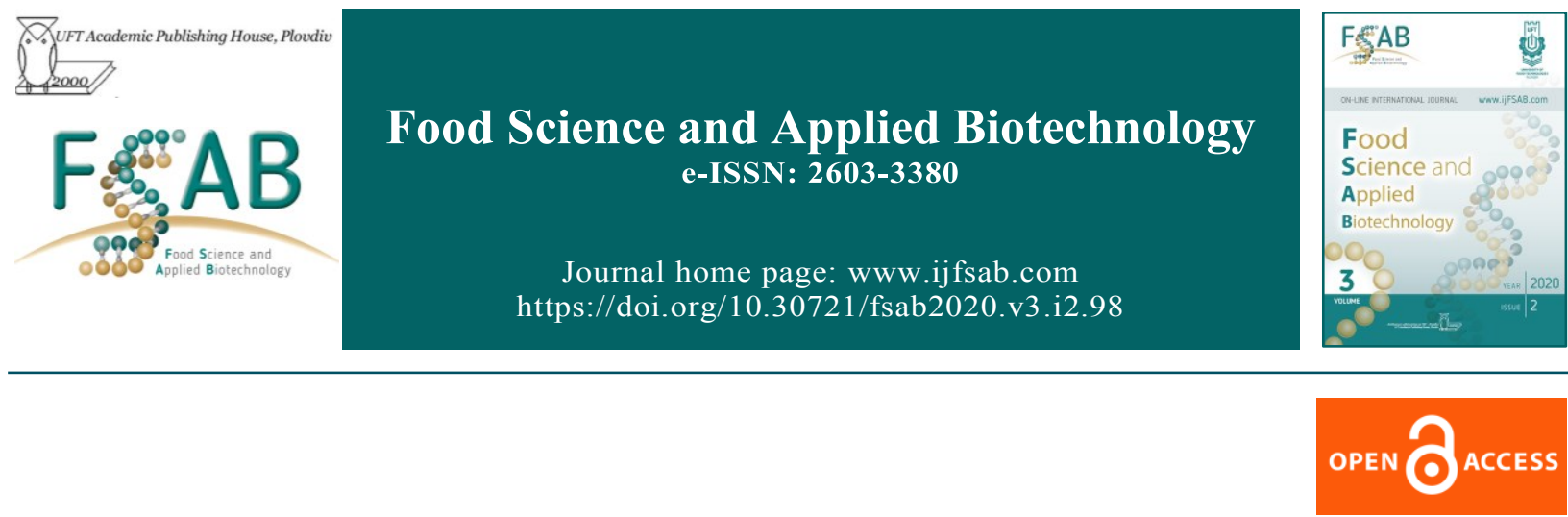

Research Article

\title{
Optimization of polyphenols extraction process with antioxidant properties from wild Vaccinium myrtillus L. (bilberry) and Vaccinium vitis-idaea L. (lingonberry) leaves
}

\author{
Radka Vrancheva ${ }^{1}$, Ivan Ivanov ${ }^{2 \varpi}$, Ilian Badjakov ${ }^{3}$, Ivayla Dincheva ${ }^{3}$, Vasil Georgiev ${ }^{4}$, \\ Atanas Pavlov ${ }^{1,4}$ \\ ${ }^{I}$ Department of Analytical Chemistry and Physical Chemistry, Technological Faculty, University of Food Technologies. Plovdiv. \\ Bulgaria \\ ${ }^{2}$ Department of Organic Chemistry and Inorganic Chemistry, Technological Faculty, University of Food Technologies. Plovdiv. \\ Bulgaria \\ ${ }^{3}$ AgroBioInstitute, Agricultural Academy, Sofia. Bulgaria \\ ${ }^{4}$ Laboratory of Cell Biosystems, The Stephan Angeloff Institute of Microbiology, Bulgarian Academy of Sciences. Plovdiv. Bulgaria
}

\section{Abstract}

The aim of the current study was to optimize the extraction condition of polyphenol compounds with antioxidant properties from leaves of natural grown Vaccinium myrtillus $\mathrm{L}$ and Vaccinium vitis-idaea L. The extractions were carried out in ultrasonic bath at $40^{\circ} \mathrm{C}$ for $20 \mathrm{~min}$ with different solvents (water, $20 \%$ ethanol, $40 \%$ ethanol, $60 \%$ ethanol, $80 \%$ ethanol and $96 \%$ ethanol) and different hydro module of samples and solvents used (1:50, 1:100 and 1:200). The highest total phenol content in the leaves of $V$. myrtillus $\mathrm{L}$. and $V$. vitis-idaea L. was found when $40 \%$ ethanol extract was used $(90.50 \pm 0.05 \mathrm{mg}$ GAE/g DW and $96.68 \pm 0.05 \mathrm{mg}$ GAE/g DW, respectively). The highest total flavonoid content of the leaves of both species was obtained with $80 \%$ ethanol as extraction solvent. The highest level of total proanthocyanidins were in the $60 \%$ ethanol extract of $V$. myrtillus L. and in the $80 \%$ ethanol extract of $V$. vitis-idaea L $(13.12 \pm 0.11 \mathrm{mg} \mathrm{LE} / \mathrm{g} \mathrm{DW}$ and $24.22 \pm 0.21 \mathrm{mg} \mathrm{LE} / \mathrm{g} \mathrm{DW}$, respectively). The highest ability to scavenge DPPH radicals possessed the $40 \%$ ethanol extracts from the leaves of both species $(693.99 \pm 4.05 \mathrm{mM} \mathrm{TE} / \mathrm{g}$ DW for $V$. myrtillus L. and $1083.18 \pm 8.48 \mathrm{mM} \mathrm{TE} / \mathrm{g}$ DW for $V$. vitisidaea $\mathrm{L}$ ). Data analysis showed that the maximal amount of polyphenols was extracted at a hydro-module of 1: 100. HPLC analysis revealed that the dominant phenolic acid in the leaves of $V$. myrtillus L was chlorogenic acid $(13.45 \mathrm{mg} / \mathrm{g} \mathrm{DW})$, while ferulic acid $(49.48 \mathrm{mg} / \mathrm{g} \mathrm{DW})$ was present at the highest concentration in the leaves of $V$. vitis-idaea $\mathrm{L}$.

Keywords: Vaccinium myrtillus L, Vaccinium vitis-idaea L, polyphenols, antioxidant activity

Abbreviations: DW - dry weight; RSM - Response Surface Methodology

${ }^{\square}$ Corresponding author: Assoc. Prof. PhD Ivan Ivanov, Department of Organic Chemistry and Inorganic Chemistry, Technological Faculty, University of Food Technologies. 26 Maritza Blvd, 4000 Plovdiv, Bulgaria, E-mail: ivanovivan.1979@yahoo.com

\section{Article history:}

Received 6 April 2020

Reviewed 4 June 2020

Accepted 4 July 2020

Available on-line 17 September 2020

https://doi.org/10.30721/fsab2020.v3.i2.98

Vrancheva et al., 2020

(C) 2020 The Authors. UFT Academic publishing house, Plovdiv Optimization of polyphenols extraction process with antioxidant ... 


\section{Introduction}

Bilberry (Vaccinium myrtillus L.) and lingonberry (Vaccinium vitis-idaea L.) are flowering plants belonging to the large genus of Vaccinium Ericaceae (Hokkanen et al., 2009; Rohloff et al., 2015; Burdulis et al., 2009) These berries are native to Bulgarian forests (Dincheva and Badjakov, 2016). The investigated Vaccinium species are mainly noted for their high content of anthocyanin pigments (Dincheva and Badjakov, 2016; Rohloff et al., 2015). Indeed, Vaccinium berries such as bilberries and blueberries lingonberry contain high amounts of sugars and organic acids. Berry fruits are rich sources of polyphenols with different bioactive potential (Hokkanen et al., 2009). These compounds are mainly represented by flavonoids, phenolic acids, and tannins, which are known as natural antioxidants (Brasanac-Vukanovic et al., 2018). Many of the biological properties are closely associated with the antioxidant activity of anthocyanin pigments (Chu et al., 2011). Riihinen et al. (2008) reported that both bilberry and blueberry leaves contained high amounts of proanthocyanidins, flavonols and hydroxycinnamic acids. Also, bilberry and lingonberry are potential sources for triterpenoid and phytosterol compounds (Szakiel et al., $2012 \mathrm{a}, \mathrm{b}$ ). The aim of the current study was to derive the most appropriate conditions for extraction of the highest yield of biologically active substances with high antioxidant potential from bilberry and lingonberry aerial part. The influence of different concentration ratio of solvent system (ethanol-water) and different hydromodules of samples and solvents on the concentration of biologically active substances have been studied.

\section{Materials and Methods}

Plant material. Aerial parts (leaves) from both Vaccinium species were collected from their natural habitats as follow: Vaccinium myrtillus L. from Gela village area $\left(41^{\circ} 38^{\prime} 32.7^{\prime \prime} \mathrm{N} 24^{\circ} 33^{\prime} 17.6 " \mathrm{E}\right)$; and Vaccinium vitis-idaea $\mathrm{L}$. from Perelic mountaintop area $\left(41^{\circ} 36^{\prime} 28.6^{\prime \prime} \mathrm{N} 24^{\circ} 35^{\prime} 46.9^{\prime \prime} \mathrm{E}\right)$ in the Rhodope mountain. The samples were finely ground using a laboratory homogenizer. The powder was used for further extraction of biologically active compounds.
Extraction procedure. One gram of dry ground leaves were placed in a flask together with $100 \mathrm{~mL}$ of ethanol-water mixture in different ratio (water, $20 \%$ ethanol, $40 \%$ ethanol, $60 \%$ ethanol, $80 \%$ ethanol and $96 \%$ ethanol) was poured in it. Ultrasound-assisted extraction was performed in an ultrasonic bath SIEL UST 5.7-150 (Gabrovo, Bulgaria) with a frequency $35 \mathrm{kHz}$, power $240 \mathrm{~W}$ at a temperature of $40^{\circ} \mathrm{C}$.

Analyses. Total polyphenols content. The total phenolics content was measured using the FolinCiocalteu assay as described by Ivanov et al. (2014): Folin-Ciocalteu reagent ( $1 \mathrm{~mL}$ ) (Sigma) diluted five times was mixed with $0.2 \mathrm{~mL}$ of sample and $0.8 \mathrm{~mL}$ $7.5 \%$ Sodium carbonate. The reaction was $20 \mathrm{~min}$ at room temperature in darkness. After reaction the absorption was measured at $765 \mathrm{~nm}$ against a blank sample, prepared in the same way but without the extract. The results were expressed in mg equivalent of gallic acid (GAE) per g dry weight (DW), values derived from a calibration curve established in the concentration range of $0.02-0.10 \mathrm{mg}$ gallic acid (Sigma) used as a standard.

Total flavonoids. Total flavonoids were determined spectrophotometrically following the method described by Ivanov et al. (2014). Each extract $(1.0 \mathrm{~mL})$ was added to test tubes containing $0.1 \mathrm{~mL} 10 \%$ aluminum nitrate (Sigma), $0.1 \mathrm{~mL} \mathrm{1M}$ potassium acetate (Sigma) and $3.8 \mathrm{~mL}$ ethanol (Merck). The reaction time was $40 \mathrm{~min}$ at ambient temperature. The absorbance was measured at 415 $\mathrm{nm}$. The results were expressed in mg equivalent of quercetin per g dry weight (DW), derived from a calibration curve, linear in the range of $10-100$ $\mu \mathrm{g} / \mathrm{mL}$ quercetin as a standard.

Total proanthocyanidins assay. Acid butanol assay for proanthocyanidins, as described by Porter et al. (1985). The six milliliter of the acid butanol reagent mixture of $950 \mathrm{~mL}$ of n-butanol and $50 \mathrm{~mL}$ concentrated $\mathrm{HCl}$ ), $0.5 \mathrm{~mL}$ aliquot of the fraction, and $0.1 \mathrm{~mL}$ of the iron reagent $(2 \%$ ferric ammonium sulfate in $2 \mathrm{~mol} / \mathrm{L} \mathrm{HCl}$ were added to a $10 \mathrm{~mL}$ screw cap tube and then vortexed. The tube was capped loosely and put in a boiling water bath for $50 \mathrm{~min}$. The absorbance of formed colored complex was read at $550 \mathrm{~nm}$. Condensed tannins were analyzed as leucocyanidin equivalent (LE) (Hagerman, 2011). 
Antioxidant activity. DPPH assay. DPPH assay was performed according to Ivanov et al. (2014). Each extract $(0.15 \mathrm{~mL})$ was mixed with $2.85 \mathrm{~mL}$ of a freshly prepared $0.1 \mathrm{mM}$ solution of 1,1-diphenyl2-picrylhydrazyl radical (DPPH, Sigma) in methanol (Merck). The reaction was performed at $37{ }^{\circ} \mathrm{C}$ in darkness and the absorptions at $517 \mathrm{~nm}$ were recorded after $15 \mathrm{~min}$ against methanol. The antioxidant activity was expressed as $\mathrm{mM}$ Trolox equivalents (TE) per g dry weight (DW) by using bration curve, established in the range of build by $0.05,0.1,0.2,0.3,0.4$ and $0.5 \mathrm{mM} 6$-hydroxy2,5,7,8-tetramethylchroman-2-carboxylic acid (Trolox ${ }^{\circledR}$, Fluka) dissolved in methanol (Sigma).

HPLC-DAD analysis of phenolic acids. Chromatographic analysis of the phenolic acids content was performed using a HPLC Elite Chrome Hitachi, coupled with diode-array detector (DAD) and ELITE LaCHrome software. The separation was performed on a reverse-phase column Supelco, Discovery ${ }^{\circledR}$ HS C18 $(5 \mu \mathrm{m}, 25 \mathrm{~cm} \times 4.6 \mathrm{~mm})$ operating at $30^{\circ} \mathrm{C}$. Detection was done at wavelength $280 \mathrm{~nm}$ and $320 \mathrm{~nm}$. Elution was performed with mobile phase A (2\% acetic acid) and mobile phase B (acetonitrile) in gradient mode described by Ivanov et al. (2014) at a flow rate 0.8 $\mathrm{mL} / \mathrm{min}$. The sample injection volume was $20 \mu \mathrm{L}$.

\section{RSM (Response Surface Methodology)} optimization method. In order to evaluate the effects of extraction parameters and to optimize conditions for various responses RSM optimization method was applied. Independent variables used in the experimental design were solvent concentration (water, 20\% ethanol, 40\% ethanol, 60\% ethanol, $80 \%$ ethanol and $96 \%$ ethanol) and sample-solvent hydro modules (1:50, 1:100 and 1:200). The coded and uncoded independent variables used in the RSM design are presented in Table 1.

Ranges of ethanol $\left(\mathrm{X}_{1}\right)$ and hydro module $\left(\mathrm{X}_{2}\right)$ and the central points were selected based on literature data. Statistical analysis of experiment was performed using Statistical Software MINITAB 16. The response variables were fitted to the following second-order polynomial model (Eq. 1), which was able to describe the relationship between the dependent output variable and the independent variables:

$$
Y=b_{0}+\sum b_{i} \mathrm{x}_{\mathrm{i}}+\sum b_{i i} \mathrm{x}_{\mathrm{i}}^{2}+\sum b_{i j} \mathrm{x}_{\mathrm{i}} \mathrm{x}_{\mathrm{j}}
$$

where

Y represents response variable (total polyphenolic content and antioxidant activity - DPPH method); $\mathrm{Xi}$ and $\mathrm{Xj}$ are the independent variables (ethanol concentration and hydro module);

$\beta 0, \beta \mathrm{i}, \beta \mathrm{ii}$ and $\beta \mathrm{ij}$ are the regression coefficients for the intercept, linear, quadratic and interaction coefficient, respectively.

Table 1. Coded and uncoded levels of independent variables used in the response surface methodology.

\begin{tabular}{lcccc}
\hline $\begin{array}{l}\text { Independent } \\
\text { variables }\end{array}$ & Symbol & $\begin{array}{c}\text { Low } \\
(-1)\end{array}$ & $\begin{array}{c}\text { Level } \\
(0)\end{array}$ & $\begin{array}{c}\text { High } \\
(+1)\end{array}$ \\
\hline $\begin{array}{l}\text { Solvent } \\
\text { concentration, } \\
\%\end{array}$ & $\mathrm{X}_{1}$ & 0 & 40 & 96 \\
$\begin{array}{l}\text { Hydro module } \\
\text { Hydle }\end{array}$ & $\mathrm{X}_{2}$ & $1: 50$ & $1: 100$ & $1: 200$ \\
\hline
\end{tabular}

\section{Results and Discussion}

There is an increasing interest for using phytochemicals from natural plants. The extracts obtained from different plant origin had different effects on human health. Extraction efficiency depends on a large number of parameters extraction method, solvents, temperature, extraction time. Therefore, it is very important to find optimal extraction parameters for obtaining extracts with the highest content of biologically active compounds (Cvetanovic et al. 2015, Mašković et al., 2016). Response surface methodology is an effective technique for the optimization of complex processes, because it allows an efficient and easier interpretation of experimental data (Bezerra et al. 2008, Zekovic et al. 2014). Several investigators already used RSM for the optimization of extraction processes in order to maximize yield of various polyphenolic compounds from various sources (Radojković et al., 2012; Claus et al., 2015; Mašković et al., 2016). In the present study RSM was used to optimize the solid-liquid extraction ratio of compounds with improved antioxidant ability from Vaccinium species. The influence of solvent composition and hydro module on the 
extraction yield of total polyphenols, total flavonoids, total proanthocyanidins and antioxidant activity was investigated. The experiments were set up according to RSM design, and the results are presented in Table 2 and Table 3. The effect of linear, quadratic or interaction coefficients on the response was tested for significance by analysis of variance. Experimental results from Table 4 were processed with multiple linear regressions using the second-order polynomial model - Eq. (1). The regression coefficients of the intercept, linear, cross product and quadratic terms are presented in the Table 4.

Suitability of the model was also analysed through the MINITAB 16. Calculated statistical parameters are presented in Table 4. According to the calculated $p$ values and the $F$ value for the suggested model was suitable for the investigated extraction system. Model equations for relationship between total phenol content and antioxidant activity and independent variables were obtained by applying multiple regression analysis (Table 4). By applying these equations, it is possible to predict values of each response. The values of $\mathrm{R}^{2}$ for total polyphenol content, and antioxidant activity were $0.73,0.94$ and 0.56 , respectively (Table 4). Therefore, it was suggested that the quadratic model fitted well with the experimental data.

The optimization procedures carried out using "Response optimizer" of MINITAB 16 software gave the following values of variable $X_{1}$ and $X_{2}$ for maximum yield of total polyphenolics, and antioxidant activities (DPPH methods) (Y) by Vaccinium species (Table 5). The deviation between the theoretically studied maximal amounts of total polyphenols and experimentally obtained for bilberry and lingonberry were $3.2 \mathrm{mg} / \mathrm{g}$ GAE DW and $5.9 \mathrm{mg} / \mathrm{g}$ GAE, respectively; and antioxidant activities (DPPH methods) (at 40\% ethanol and 1:100 hydro module) under ultrasonic influence (Table 5). On this basis, we propose that $40 \%$ ethanol in water and hydro module 1:100 as optimal extraction conditions for highest yield of biologically actives substances from Vaccinium species leaves.

According to the obtained results, all investigated extracts of lingonberry contained a higher total polyphenol content and higher ability to scavenge DPPH radicals than the extracts of bilberry leaves, while a higher total flavonoid content was determined in the extracts of bilberry leaves.

After establishing the optimal parameters (40\% ethanol and 1:100 hydro modules) for extraction of the highest amount of polyphenol components by ultrasonic irradiation, HPLC-DAD analysis of phenolic acids was carried out.

The results showed the presence of three phenolic acids in the bilberry leaves: chlorogenic acid $13.45 \mathrm{mg} / \mathrm{g} \mathrm{DW}$, p-coumaric acid - $0.62 \mathrm{mg} / \mathrm{g} \mathrm{DW}$ and sinapic acid $-1.85 \mathrm{mg} / \mathrm{g}$ DW. The main phenolic acid extracted from lingonberry leaves was ferulic acid $-49.48 \mathrm{mg} / \mathrm{g}$ DW, followed by sinapic acid $(2.34 \mathrm{mg} / \mathrm{g} \mathrm{DW})$ and chlorogenic acid $(2.55$ $\mathrm{mg} / \mathrm{g}$ DW) (Table 6). Brasanac-Vukanovic et al. (2018) investigated the phenolic compounds in different extracts obtained from bilberry leaves and obtained similar results - the main phenolic acid was chlorogenic acid (from 45.5 to $59.7 \mathrm{mg} / \mathrm{g} \mathrm{DW}$ ), followed by p-coumaric acid (from 1.26 to 2.08 $\mathrm{mg} / \mathrm{g}$ DW).

\section{Conclusions}

The optimal conditions for the extraction of biologically active substances from Vaccinium myrtillus L. and Vaccinium vitis-idaea L. are as follow: $40 \%$ ethanol-water as solvent system and hydro module 1:100 in ultrasound bath with frequency $35 \mathrm{kHz}$. Under these condition the maximum amount of total polyphenols content and antioxidant activity was obtained. The main identified phenolic acid in the $40 \%$ ethanol-water extract in bilberry leaves was chlorogenic acid and for lingonberry extract was ferulic acid.

\section{Acknowledgements}

The authors are thankful for the financial support of Bulgarian Science Fund, Bulgarian Ministry of Education and Science by contract ДН 16/1 11.12.2017 
Table 2. Experimental matrix and values of the observed responses of total polyphenolics, and antioxidant activities (DPPH methods) for bilberry.

\begin{tabular}{lccccc}
\hline Sample & $\begin{array}{c}\text { Hydro- } \\
\text { module }\end{array}$ & $\begin{array}{c}\text { Total polyphenol } \\
\text { contents, } \\
\text { mg GAE/g DW }\end{array}$ & $\begin{array}{c}\text { Total } \\
\text { flavonoids, } \\
\text { mg QE/g DW }\end{array}$ & $\begin{array}{c}\text { Total } \\
\text { proanthocyanidins, } \\
\text { mg LE/g DW }\end{array}$ & $\begin{array}{c}\text { Antioxidant } \\
\text { ability, } \\
\text { mM TE/g DW }\end{array}$ \\
\hline Water & $1: 100$ & $65.04 \pm 0.10$ & $24.64 \pm 0.06$ & $10.68 \pm 0.21$ & $507.59 \pm 8.75$ \\
$20 \%$ Ethanol & $1: 100$ & $68.39 \pm 0.19$ & $28.54 \pm 0.27$ & $11.08 \pm 0.18$ & $573.62 \pm 2.73$ \\
$40 \%$ Ethanol & $1: 100$ & $90.50 \pm 0.05$ & $26.47 \pm 0.47$ & $11.73 \pm 0.21$ & $693.99 \pm 4.05$ \\
$60 \%$ Ethanol & $1: 100$ & $71.16 \pm 0.15$ & $31.27 \pm 0.17$ & $13.12 \pm 0.11$ & $667.40 \pm 2.88$ \\
$80 \%$ Ethanol & $1: 100$ & $70.98 \pm 0.35$ & $34.96 \pm 0.17$ & $12.34 \pm 0.16$ & $601.11 \pm 4.33$ \\
$96 \%$ Ethanol & $1: 100$ & $56.40 \pm 0.21$ & $23.80 \pm 0.17$ & $12.04 \pm 0.06$ & $456.05 \pm 8.75$ \\
$40 \%$ Ethanol & $1: 50$ & $58.62 \pm 0.24$ & $28.50 \pm 0.38$ & $1.66 \pm 0.03$ & $668.13 \pm 5.54$ \\
$40 \%$ Ethanol & $1: 200$ & $61.24 \pm 0.28$ & $32.58 \pm 0.69$ & $1.51 \pm 0.06$ & $633.96 \pm 9.27$ \\
\hline
\end{tabular}

Table 3. Experimental matrix and values of the observed responses of total polyphenols, and antioxidant activities (DPPH methods) for lingonberry.

\begin{tabular}{lccccc}
\hline Sample & $\begin{array}{c}\text { Hydro- } \\
\text { module }\end{array}$ & $\begin{array}{c}\text { Total polyphenol } \\
\text { contents, } \\
\text { mg GAE/g DW }\end{array}$ & $\begin{array}{c}\text { Total } \\
\text { flavonoids, } \\
\text { mg QE/g DW }\end{array}$ & $\begin{array}{c}\text { Total } \\
\text { proanthocyanidins, } \\
\text { mg LE/g DW }\end{array}$ & $\begin{array}{c}\text { Antioxidant } \\
\text { ability, } \\
\text { mM TE/g DW }\end{array}$ \\
\hline Water & $1: 100$ & $79.91 \pm 1.31$ & $15.16 \pm 0.16$ & $7.78 \pm 0.25$ & $544.16 \pm 8.09$ \\
20\% Ethanol & $1: 100$ & $84.13 \pm 0.83$ & $16.82 \pm 0.10$ & $10.93 \pm 1.18$ & $858.46 \pm 4.09$ \\
40\% Ethanol & $1: 100$ & $96.68 \pm 0.68$ & $13.62 \pm 0.27$ & $13.05 \pm 0.60$ & $1083.18 \pm 8.48$ \\
60\% Ethanol & $1: 100$ & $75.98 \pm 0.35$ & $15.81 \pm 0.10$ & $11.45 \pm 1.30$ & $928.04 \pm 9.05$ \\
$80 \%$ Ethanol & $1: 100$ & $77.95 \pm 0.20$ & $21.20 \pm 0.40$ & $24.22 \pm 0.22$ & $652.02 \pm 8.67$ \\
96\% Ethanol & $1: 100$ & $78.68 \pm 0.10$ & $13.69 \pm 0.23$ & $12.75 \pm 0.23$ & $864.07 \pm 6.03$ \\
$40 \%$ Ethanol & $1: 50$ & $88.43 \pm 0.05$ & $16.88 \pm 0.22$ & $5.17 \pm 0.13$ & $959.95 \pm 9.69$ \\
$40 \%$ Ethanol & $1: 200$ & $92.05 \pm 0.15$ & $19.78 \pm 0.61$ & $6.32 \pm 0.46$ & $922.56 \pm 5.80$ \\
\hline
\end{tabular}


Table 4. Regression equation coefficients for the selected responses

\begin{tabular}{|c|c|c|c|c|c|c|}
\hline Variable & $\begin{array}{c}\text { Regression } \\
\text { coefficient }\end{array}$ & F-value & p-value & $\begin{array}{c}\text { Regression } \\
\text { coefficient }\end{array}$ & F-value & p-value \\
\hline \multicolumn{7}{|c|}{ Total polyphenols concentration } \\
\hline & \multicolumn{3}{|c|}{ Bilberry } & \multicolumn{3}{|c|}{ Lingonberry } \\
\hline Intercept $b_{0}$ & -0.69 & & & 89.48 & & \\
\hline Linear & & 2.90 & 0.199 & & 0.05 & 0.949 \\
\hline$b_{i}$ & 0.77 & 0.35 & 0.594 & 0.24 & 0.01 & 0.918 \\
\hline$b_{j}$ & 1.05 & 5.72 & 0.097 & -0.14 & 0.10 & 0.770 \\
\hline Square (quadratic) & & 4.11 & 0.138 & & 0.83 & 0.515 \\
\hline$b_{i i}$ & $-8.82 \times 10^{-3}$ & 5.58 & 0.099 & $-3.23 \times 10^{-3}$ & 0.76 & 0.448 \\
\hline$b_{j j}$ & $-4.10 \times 10^{-3}$ & 6.51 & 0.084 & $0.68 \times 10^{-3}$ & 0.18 & 0.699 \\
\hline $\mathrm{R}^{2 \mathrm{a}}$ & 0.739 & & & 0.472 & & \\
\hline \multicolumn{7}{|c|}{ Antioxidant activity } \\
\hline & \multicolumn{3}{|c|}{ Bilberry } & \multicolumn{3}{|c|}{ Lingonberry } \\
\hline Intercept $b_{0}$ & 452.085 & & & 626.75 & & \\
\hline Linear & & 3.53 & 0.163 & & 0.94 & 0.482 \\
\hline$b_{i}$ & 8.22 & 7.07 & 0.076 & 13.95 & 1.83 & 0.269 \\
\hline$b_{j}$ & 0.74 & 0.16 & 0.720 & -0.28 & 0.00 & 0.972 \\
\hline Square (quadratic) & & 22.23 & 0.016 & & 1.84 & 0.302 \\
\hline$b_{i i}$ & $-87.56 \times 10^{-3}$ & 37.65 & 0.009 & -0.13 & 2.83 & 0.191 \\
\hline$b_{i j}$ & $-3.87 \times 10^{-3}$ & 0.39 & 0.577 & $0.12 \times 10^{-3}$ & 0.00 & 0.997 \\
\hline $\mathrm{R}^{2 \mathrm{a}}$ & 0.938 & & & 0.564 & & \\
\hline
\end{tabular}

Table 5. Comparison between theoretically calculated and experimentally obtained yields of total polyphenolics, and antioxidant activities of bilberry and lingonberry extracts.

\begin{tabular}{lccccccc}
\hline & \multicolumn{8}{c}{ Theoretically calculated } & \multicolumn{3}{c}{ Experimentally obtained } & Deviation between \\
& $\mathbf{X}_{\mathbf{1}}{ }^{1}$ & $\mathbf{X}_{\mathbf{2}}{ }^{1}$ & $\overline{\mathbf{Y}}$ & $\mathbf{X}_{\mathbf{1}}$ & $\mathbf{X}_{\mathbf{2}}$ & $\mathbf{Y}$ & $\overline{\mathbf{Y}}$ and $\mathbf{Y}$ \\
\hline \multicolumn{7}{c}{ Total polyphenols } \\
Bilberry & 48.0 & $1: 125$ & 83.3 & 40 & $1: 100$ & 90.5 & $7.9 \%$ \\
Lingonberry & 34.0 & $1: 200$ & 92.0 & 40 & $1: 100$ & 96.7 & $4.8 \%$ \\
& \multicolumn{7}{c}{ Antioxidant activity } \\
Bilberry & 46.5 & $1: 96$ & 680.4 & 40 & $1: 100$ & 694.0 & $2.0 \%$ \\
Lingonberry & 52.8 & $1: 50$ & 981.8 & 40 & $1: 100$ & 1083.2 & $9.3 \%$ \\
\hline
\end{tabular}


Table 6. HPLC analysis of phenolic acids in the $40 \%$ ethanol extracts (1:100 hydro modules) of $V$. myrtillus and $V$. vitis-idaea leaves

\begin{tabular}{lcc}
\hline Compounds & $\begin{array}{c}\text { Bilberry } \\
\text { V. myrtillus, } \\
\text { mg/g DW }\end{array}$ & $\begin{array}{c}\text { Lingonberry } \\
\text { V.vitis-idaea, } \\
\text { mg/g DW }\end{array}$ \\
\hline Chlorogenic acid & 13.45 & 2.55 \\
Caffeic acid & nd & 0.36 \\
Ferulic acid & nd & 49.48 \\
-Coumaric acid & 5.04 & 1.48 \\
Sinapic acid & 1.85 & 2.34 \\
\hline
\end{tabular}

nd - not detected

\section{References}

Bezerra M. A., Santelli R. E., Oliveira E.P., Villar L.S., Escaleira L.A. Response surface methodology (RSM) as a tool for optimization in analytical chemistry. Talanta, 2008, 76(5): 965-977. https://doi.org/10.1016/j.talanta.2008.05.019

Brasanac-Vukanovic S., Mutic J., Stankovic D. M., Arsic I., Blagojevic N., Vukasinovic-Pesic V., Tadic V. M. Wild bilberry (Vaccinium myrtillus L., Ericaceae) from Montenegro as a source of antioxidants for use in the production of nutraceuticals, Molecules, 2018, 23(8): 1864. https://doi.org/10.3390/molecules23081864

Burdulis D., Sarkinas A., Jasutiené I., Stackevicené E., Nikolajevas L., Janulis V. Comparative study of anthocyanin composition, antimicrobial and antioxidant activity in bilberry (Vaccinium myrtillus L.) and blueberry (Vaccinium corymbosum L.) fruits. Acta Poloniae Pharmaceutica - Drug Research. 2009, 66(4): 399-408.

Chu W., Cheung S. C. M., Lau R. A.W., Benzie I. F. F. Bilberry (Vaccinium myrtillus L.) NCBI Bookshelf. In: Herbal Medicine: Biomolecular and Clinical Aspects. (2 ${ }^{\text {nd }}$ Edition), (I.F.F. Benzie, S. WachtelGalor Eds.). CRC Press, Taylor \& Francis Group. 2011, pp. 55-72, ISBN-13: 978-1439807132, ISBN10: 1439807132
Claus T., Palombini S.V., Carbonera F., Figueiredo I.L., Matsushita M., Visentainer J.V. Response surface methodology applied in the study of emulsion formulations in the presence of leaves of rosemary (Rosmarinus officinalis L.) as a source of natural antioxidants. Journal of the Brazilian Chemical Society, 2015, 26(10): 2097-2104. http://doi.org/10.5935/0103-5053.20150195

Cvetanović A., Švarc-Gajić J., Mašković P., Savić S., Nikolić L.J. Antioxidant and biological activity of chamomile extracts obtained by different techniques: perspective of using superheated water for isolation of biologically active compounds. Industrial Crops and Products, 2015, 65(3):582-591. https://doi.org/10.1016/j.indcrop.2014.09.044

Dincheva I., Badjakov I. Assessment of the anthocyanin variation in Bulgarian bilberry (Vaccinium myrtillus L.) and lingonberry (Vaccinium vitis-idaea L.). International Journal of Medicine and Pharmaceutical Science, 2016, 6(3): 39-50. Available at: https://papers.ssrn.com/sol3/papers.cfm?abstract id= $\underline{2838677}$

Hagerman, A., 2011. The Tannin Handbook. Available at: http://www.users.muohio.edu/hagermae

Hokkanen J., Mattila S., Jaakola L., Pirttila A. M., Tolonen A. Identification of phenolic compounds from lingonberry (Vaccinium vitis-idaea L.), bilberry (Vaccinium myrtillus L.) and hybrid bilberry (Vaccinium x intermedium Ruthe L.) leaves. Journal of Agricultural and Food Chemistry, 2009, 57(20):

9437-9447. https://doi.org/10.1021/jf9022542

Ivanov I., Vrancheva R., Marchev A., Petkova N., Aneva I., Denev P., Georgiev V., Pavlov A. Antioxidant activities and phenolic compounds in Bulgarian Fumaria species. International Journal of Current Microbiology and Applied Science, 2014, 3(2): 296-306. Available at: https://pdfs.semanticscholar.org/3be9/df25ed8c217e d42ca21b00b7efbee45bbf14.pdf 
Mašković P. Z., Diamanto L. D., Cvetanović A., Radojković M., Spasojević M. B., Zengin G. Optimization of the extraction process of antioxidants from orange using response surface methodology. Food Analytical Methods, 2016, 9(5): 1436-1443. https://doi.org/10.1007/s12161-015$\underline{0321-5}$

Porter L. J., Hrstich L. N., Chan B. C. The conversion of urocyanidins and prodelphinidins to cyanidin and delphinidin. Phytochemistry, 1985, 25(1): 223-230. https://doi.org/10.1016/S0031-9422(00)94533-3

Radojković M., Zeković Z., Jokić S., Vidović S., Lepojević Z., Milošević S. Optimization of solidliquid extraction of antioxidants from black mulberry leaves by response surface methodology. Food Technology and Biotechnology, 2012, 50(2): 167-176. Available at: https://hrcak.srce.hr/index.php?show=clanak\&id cla $\underline{\text { nak jezik }=124077}$

Riihinen K., Jaakola L., Kärenlampi S., Hohtola A. Organ-specific distribution of phenolic compounds in bilberry (Vaccinium myrtillus) and 'north blue' blueberry (Vaccinium corymbosum $\mathrm{x} V$. angustifolium). Food Chemistry, 2008, 110(1): 156160. https://doi.org/10.1016/j.foodchem.2008.01.057

Rohloff J., Uleberg E., Nes A., Krogstad T., Nestby R., Martinussen I. Nutritional composition of bilberries (Vaccinium myrtillus $\mathrm{L}$.) from forest fields in Norway - Effects of geographic origin, climate, fertilization and soil properties. Journal of Applied Botany and Food Quality, 2015, 88(2015): 274-287. https://doi.org/10.5073/JABFQ.2015.088.040

Szakiel A., Pączkowski C., Huttunen S. Triterpenoid content of berries and leaves of bilberry Vaccinium myrtillus from Finland and Poland. Journal of Agricultural and Food Chemistry, 2012a, 60(48): 11839-11849. https://doi.org/10.1021/jf3046895

Szakiel A., Paczowski C., Koivuniemi H., Huttunen S Comparison of the triterpenoids content of berries and leaves of lingonberry Vaccinium litisidaea from Finland and Poland. Journal of Agricultural and Food Chemistry, 2012b, 60(19): 4994-5002. https://doi.org/10.1021/jf300375b
Zeković Z., Cvetanović A., Pavlić B., Švarc-Gajić J., Radojković M. Optimization of the polyphenolics extraction from chamomile ligulate flowers using response surface methodology. International Journal of Plant Research, 2014, 4(2): 43-50. https://doi.org/10.5923/j.plant.20140402.01 